\title{
The Nightmare of Obstructive Mechanical Valve Thrombosis: What is the Optimal Care?
}

\author{
Jamal EL Ouazzani, Fadoua Mouedder, Noha El Ouafi, Nabila Ismaili \\ Department of Cardiology, Mohammed VI University Hospital, Laboratory of Epidemiology and Public Health, Faculty of Medicine and Pharmacy, University \\ Mohammed First of Oujda, Oujda, Morocco
}

ORCID:

Jamal EL Ouazzani: https://orcid.org/0000-0002-6800-7538

Fadoua Mouedder: https://orcid.org/0000-0001-6528-2991

Noha El Ouafi: https://orcid.org/0000-0002-9907-0337

Nabila Ismaili: https://orcid.org/0000-0001-5596-418X

\section{Abstract}

Obstructive mechanical valve thrombosis is a rare and serious disease. Despite therapeutic progress, mortality remains high, and the choice between surgery and thrombolytic therapy remains controversial. We report the case of a 46-year-old woman admitted to the emergency department for obstructive mitral mechanical valve thrombosis successfully thrombolyzed by the recombinant tissue plasminogen activator. Through this case, we would like to discuss the different therapeutic options, and why fibrinolysis was our choice for this particular patient.

Keywords: Mechanical valve thrombosis, obstructive, surgery, thrombolytic therapy

\section{INTRODUCTION}

Obstructive mechanical valve thrombosis is a rare situation with an annual incidence of $0.3-1.3 / 100$ patients, but it is the most serious complication of mechanical prostheses. There are two types of clinical presentation, obstructive and nonobstructive thrombosis. Obstructive thrombosis presents with respiratory and hemodynamic instability and requires urgent management, whereas systemic embolism is the major risk of nonobstructive thrombosis. In this case report, we will focus on the controversial therapeutic management of obstructive thrombosis: optimization of anticoagulation, fibrinolysis, or surgery.

\section{Case Report}

A 46-year-old female with a history of a severe rheumatic mitral disease who underwent 1 year ago mitral bileaflet mechanical valve prosthesis replacement with tricuspid annuloplasty, after which she was put on acenocoumarol, spironolactone, and atenolol, was admitted to our hospital for respiratory and

Received: 25-03-2020 Revised: 14-05-2020 Accepted: 26-05-2020

Published Online: 27-11-2020

\begin{tabular}{|l|l|}
\hline \multicolumn{3}{|c|}{ Access this article online } \\
\hline Quick Response Code: & Website: \\
& \\
http://www.ijcva.com
\end{tabular}

hemodynamic distress. Anticoagulation had been stopped 3 days before the admission against medical advice because of an episode of epistaxis. The patient presented to the emergency room for dyspnea at rest, with orthopnea, associated with chest tightness and intermittent palpitations. On presentation, vitals were as follows: oral temperature of $37.8^{\circ} \mathrm{C}$, blood pressure of $90 / 60 \mathrm{mmHg}$, heart rate of 170 beats/min, and respiratory rate of 30 breaths/min, with an oxygen saturation $\left(\mathrm{SpO}_{2}\right)$ of $65 \%$ on room air and of $85 \%$ under $10 \mathrm{~L}$ of oxygen. The patient was alert and oriented. Physical examination revealed signs of acute decompensated heart failure and muffling of the prosthetic heart valve sounds. Electrocardiography showed atrial fibrillation with a ventricular rhythm at $170 \mathrm{bpm}$. A chest X-ray showed signs of pulmonary edema. Laboratory tests revealed elevated level of NT-proBNP and an The

Address for correspondence: Dr. Jamal El Ouazzani,

Department of Cardiology, Mohammed VI University Hospital, Laboratory of Epidemiology and public Health, Faculty of Medicine and Pharmacy, University Mohammed First of Oujda, 60049 Oujda, Morocco. E-mail: j.elouazzani.cardio@gmail.com

This is an open access journal, and articles are distributed under the terms of the Creative Commons Attribution-NonCommercial-ShareAlike 4.0 License, which allows others to remix, tweak, and build upon the work non-commercially, as long as appropriate credit is given and the new creations are licensed under the identical terms.

For reprints contact: WKHLRPMedknow_reprints@wolterskluwer.com

How to cite this article: EL Ouazzani J, Mouedder F, El Ouafi N, Ismaili N. The nightmare of obstructive mechanical valve thrombosis: What is the optimal care? Int J Cardiovasc Acad 2020;6:176-9. 
international normalised ratio (INR) of 1,5 , however renal function and complete blood count were normal. Transthoracic echocardiography (TTE) revealed a mean transprosthetic mitral gradient of $20 \mathrm{mmHg}$ [Figure 1a], a dilated left atrium without visible thrombus and severe pulmonary hypertension. cinefluoroscopy performed an emergency confirmed the prosthetic valve obstruction [Figure 1c and d].

After putting the patient on noninvasive ventilation and furosemide, she received fibrinolysis using recombinant tissue plasminogen activator (rt-PA) (alteplase): $10 \mathrm{mg}$ bolus $+90 \mathrm{mg}$ in 90 min with unfractionated heparin (UFH). Forty minutes after the start of fibrinolysis, there was a hemodynamic and respiratory improvement: blood pressure was $120 / 80 \mathrm{mmHg}$, heart rate was $97 \mathrm{bpm}$, and $\mathrm{SpO}_{2}$ was $90 \%$ on room air with a clear regression of crackles. TTE showed a significant drop in the transmitral mean gradient to $8 \mathrm{mmHg}$. The TTE performed $48 \mathrm{~h}$ after admission showed a normal prosthetic function with a transprosthetic mean gradient at $5 \mathrm{mmHg}$ [Figure 1b]. Transesophageal echocardiography (TEE) performed after patient stabilization showed normal prosthetic motion without an image of prosthetic or atrial thrombus. During the hospital stay, there was a normalization of all hemodynamic and respiratory parameters without any hemorrhagic or embolic events. We kept the patient on UFH until having an INR of 3.5.

\section{Discussion}

The treatment of symptomatic obstructive mechanical valve thrombosis is surgery and thrombolytic therapy. Surgical treatment consists of a thrombectomy or a valve replacement preferably by biological valve to prevent recurrences in these patients considered to be at high risk of thromboembolic recurrence. Old publications considered this surgery to be a very high-risk surgery with a reported operative mortality rate in the case of the New York Heart Association (NYHA) class IV of $50 \%$. Thanks to the progress in surgical techniques and anesthesia, there has been an improvement in the prognosis

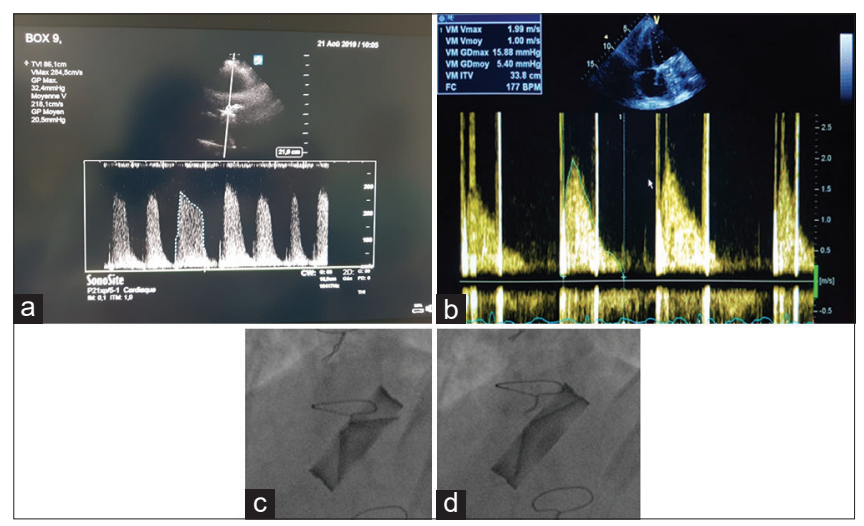

Figure 1: (a) Transthoracic echocardiography performed in the emergency room showing a mean transprosthetic mitral gradient of $20 \mathrm{mmHg}$; (b) Transthoracic echocardiography showing normalization of transprosthetic mean gradient $(5 \mathrm{mmHg}) 4 \mathrm{~h}$ after starting thrombolytic therapy. Cinefluoroscopy showing almost complete blocking leaflets in closed position. (c) diastolic image, (d) systolic image with mortality rates ranging from $5 \%$ to $15 \%$ depending on the severity of clinical presentation and NYHA class. ${ }^{[1]}$ Like surgery, fibrinolysis results improved over time with an increase in hemodynamic efficiency rising from $75 \%$ to $90 \%$ and a considerable decrease in fatal and major complications: decrease in embolic complications from $13 \%$ to $<2 \%$, hemorrhagic complications from $6 \%$ to $<2 \%$, and death from $7 \%$ to $3 \%$. This is due to the use of the new generation of thrombolytic agents and small doses - slow infusion protocols. However, the success and complications depend above all on the clinical presentation and the thrombus size if it is visible. After thrombolytic therapy, recurrence is frequent (19\%), especially in cases of mitral prostheses.

\section{Facing an obstructive mechanical valve thrombosis, should surgery or fibrinolysis be preferred?}

A meta-analysis, published in 2014 by CASTILHO, had shown that the incidence of operative mortality was higher than that observed with fibrinolysis: operative mortality was $18.1 \%$ versus $6.6 \%$ for thrombolytic therapy, and that surgical mortality appeared to increase with the NYHA class. Embolic and hemorrhagic events were more common in thrombolysis: $4.6 \%$ versus $12 \%$ and $4.6 \%$ versus 6.8 , respectively. Hemodynamic success rates were comparable between the two methods ( $81.9 \%$ for surgery vs. $80.7 \%$ for fibrinolysis). However, this meta-analysis included only observational studies since the literature did not have a randomized study. ${ }^{[2]}$

A comparative retrospective study carried out at the University Hospital Center of Bordeaux, France, by Professor Roudaut's team compared the results of the two therapeutic methods, showed a high rate of hemodynamic success with the two options with a slight superiority in favor of surgery $(88.9 \%$ vs. $70.9 \%)$. Embolic and hemorrhagic events were more frequent with fibrinolysis ( $15 \%$ vs. $0.7 \%$ and 3.9 vs. $0.7 \%$, respectively), mortality was comparable ( $11.8 \%$ vs. $10.4 \%)$, and recurrence was greater with fibrinolysis (18.9\% vs. $7.4 \%) \cdot{ }^{[3]}$ Another meta-analysis published by Grace et al. ${ }^{[4]}$ had shown that thrombolytic therapy was associated with a higher complication rate compared to surgery and that the mortality rate was higher with surgery compared to thrombolysis ( $15 \%$ for surgery vs. $8 \%$ for thrombolysis), but it should be noted that the patients who underwent surgery were more serious than those who underwent thrombolysis.

Karthikeyan et al. ${ }^{[1]}$ had shown through their meta-analysis that urgent surgery was not superior to fibrinolysis to restore valvular function, but it reduced considerably the occurrence of major thromboembolic and hemorrhagic events and the recurrence of valvular thrombosis. Awaiting the results of randomized controlled trials, urgent surgery should probably be preferred to thrombolysis for obstructive left mechanical valve thrombosis [Table 1].

\section{If the choice of thrombolysis is made, which protocol should be used?}

Searching for the best agent and fibrinolytic protocol, a lot of studies have been published. The study by Özkan et al.,$^{[5]}$ 


\begin{tabular}{|c|c|c|}
\hline \multicolumn{3}{|c|}{$\begin{array}{l}\text { Table 1: Summary table of the hemodynamic } \\
\text { effectiveness, hemorrhagic, embolic complications and } \\
\text { death risk of thrombolysis, and surgery in the treatment } \\
\text { of left mechanical valve thrombosis }\end{array}$} \\
\hline & Fibrinolysis & Surgery \\
\hline Hemodynamic success & ++ & +++ \\
\hline Hemorrhage & ++ & + \\
\hline Embolism & +++ & + \\
\hline Death & ++ & $++(+)$ \\
\hline
\end{tabular}

which is a monocentric, prospective, nonrandomized study, had compared five protocols: rapid streptokinase infusion (Group I), slow infusion (Group II), a t-PA at full dose (100 mg) (Group III), at half dose of $50 \mathrm{mg}$ with slow infusion over $6 \mathrm{~h}$ without a bolus (Group IV), and a low dose of $25 \mathrm{mg}$ in slow infusion over $6 \mathrm{~h}$ without bolus (Group V). The comparison between these different protocols had shown that the slow infusion of 25 mg of t-PA over $6 \mathrm{~h}$ without bolus was the safest thrombolytic treatment with the lowest complication and mortality rates without loss of efficacy. However, it should be noted that almost $50 \%$ of the patients included in the different groups had nonobstructive thrombosis, the thrombi were often small, and the majority of patients were clinically stable. It is important to keep these limitations in mind before applying the findings of this study in practice. Another study carried out by the same author had confirmed the results of the previous study, and it showed that the ultraslow infusion over $25 \mathrm{~h}$ of a low dose of t-PA ( $25 \mathrm{mg}$ ) (an infusion of $1 \mathrm{mg} / \mathrm{h}$ of rt-PA) without bolus was associated with a low risk of nonfatal complications and mortality except for patients with a class IV NYHA. This protocol could be effective in stable patients. ${ }^{[6]}$

The widely used thrombolytic in myocardial infarction was tenecteplase (TNK). A study published by Kathirvel et al. ${ }^{[7]}$ compared TNK thrombolysis $(0.5 \mathrm{mg} / \mathrm{kg}$ in a slow infusion of $24 \mathrm{~h}$ ) to streptokinase (SK) (intravenous bolus of 250,000 IU during $30 \mathrm{~min}$, followed by intravenous infusion of 100,000 $\mathrm{IU} / \mathrm{h}$ during $24 \mathrm{~h}$ ). Thrombolysis was repeated up to 3 times (72 h) in the SK-based protocol and up to 2 times ( $48 \mathrm{~h}$ ) in the TNK-based protocol until normalization of the transvalvular gradient. This study did not show any significant difference in the efficacy, hemorrhagic, and embolic complications between the two groups.

In summary, there is no consensus regarding the best fibrinolytic and protocol. A simple therapeutic strategy can be proposed with two types of protocols depending on the patient's clinical presentation:

- A short protocol " rescue protocol" should be preferred in case of hemodynamic instability. It consists of using a fibrinolytic with a short half-life, strong specificity to fibrin, rapid and short infusion time like rt-PA at high doses

- Otherwise, in case of hemodynamic stability, we feel that it is preferable to use a protocol with low doses of thrombolytic drugs and a prolonged slow infusion; we can even sometimes divide the doses to reduce the risk of thromboembolic and hemorrhagic complications.

The predictors of the success of the thrombolytic treatment are a recent problem of anticoagulation therapy, the absence of stroke history, and the absence of large clot $>0.8 \mathrm{~cm}^{2}$ at TEE. ${ }^{[8]}$ These three criteria were present in our patient.

\section{What do the guidelines say?}

Concerning the ESC guidelines, ${ }^{[9]}$ an urgent valve replacement, preferably with a biological prosthesis, is recommended in obstructive mechanical prosthetic valve thrombosis outside the high surgical risk (Class I, Level C). Fibrinolysis should be considered in the case of unavailable surgery or patients with significant comorbidities and high surgical risk or the case of a right heart prosthesis (Class IIa, Level C). In the case of hemodynamic stability with a recent anticoagulation problem, the anticoagulant treatment must be optimized. If failure, consider thrombolysis if the surgical risk is high or unavailability of surgery, otherwise opt for surgery. Surgery should be considered as the first line of treatment if there is no recent anticoagulant therapy problem.

Regarding the American Heart Association/American College of Cardiology (AHA/ACC) guidelines, ${ }^{[10]}$ urgent initial treatment with low-dose and slow-infusion fibrinolytic regimens, since this type of regimens has higher success rates and lower complication rates than priopr high-dose regimens, or emergency surgery in the patient with a left-sided mechanical prosthetic valve thrombosis. The decision for emergency surgery versus fibrinolytic therapy should be based on multiple factors according to AHA/ACC guidelines [Table 2] including the availability of surgical expertise and the clinical experience with both treatments.

For thrombosed right-sided prosthetic heart valves, fibrinolytic therapy is reasonable according to ESC and AHA/ACC guidelines in patients with NYHA functional Class III-IV symptoms or large clot burden (Level of Evidence C). ${ }^{[9,10]}$

\section{Conclusion}

Obstructive mechanical valve thrombosis remains a diagnostic and therapeutic challenge. The optimal treatment remains controversial requiring multidisciplinary management. Despite the absence of recommendations with a high level of evidence, there is a feeling that surgical treatment remains the treatment of choice in patients with a critical clinical presentation, whereas fibrinolytic treatment remains the choice in case of hemodynamic stability and valvular prosthetic thrombosis of the right heart. This case report shows that fibrinolytic treatment can be used as an effective and safe alternative to surgery even in critical clinical situations.

"Patients who have undergone valve replacement are not cured but still have serious heart disease" the patient was consented to the publication of the article. 


\begin{tabular}{|c|c|}
\hline \multicolumn{2}{|c|}{$\begin{array}{l}\text { Table 2: Factors according to the American Heart } \\
\text { Association/American College of Cardiology guidelines } \\
\text { to make the decision for emergency surgery versus } \\
\text { fibrinolytic therapy }\end{array}$} \\
\hline Favor surgery & Favor fibrinolysis \\
\hline Readily available surgical expertise & No surgical expertise available \\
\hline Low surgical risk & High surgical risk \\
\hline Contraindication to fibrinolysis & $\begin{array}{l}\text { No contraindication to } \\
\text { fibrinolysis }\end{array}$ \\
\hline Recurrent valve thrombosis & $\begin{array}{l}\text { First-time episode of valve } \\
\text { thrombosis }\end{array}$ \\
\hline NYHA class IV & NYHA class I-III \\
\hline Large clot $\left(>0.8 \mathrm{~cm}^{2}\right)$ & Small clot $\left(\leq 0.8 \mathrm{~cm}^{2}\right)$ \\
\hline Left atrial thrombus & No left atrial thrombus \\
\hline $\begin{array}{l}\text { Concomitant } \mathrm{CAD} \text { in need of } \\
\text { revascularization }\end{array}$ & No or mild CAD \\
\hline Other valve disease & No other valve disease \\
\hline Possible pannus & Thrombus visualized \\
\hline Patient choice & Patient choice \\
\hline \multicolumn{2}{|c|}{$\begin{array}{l}\text { The bold factors were present in our patient (seven factors in favor } \\
\text { of fibrinolysis versus two in favor of surgery). CAD: Coronary artery } \\
\text { disease; NYHA: New York Heart Association, ACC/AHA: American } \\
\text { College of Cardiology/American Heart Association }\end{array}$} \\
\hline \multicolumn{2}{|l|}{ Declaration of patient consent } \\
\hline \multicolumn{2}{|c|}{$\begin{array}{l}\text { The authors certify that they have obtained all appropriate } \\
\text { patient consent forms. In the form, the patient has given her } \\
\text { consent for her images and other clinical information to be } \\
\text { reported in the journal. The patient understands that name and } \\
\text { initials will not be published and due efforts will be made to } \\
\text { conceal identity, but anonymity cannot be guaranteed. }\end{array}$} \\
\hline \multicolumn{2}{|c|}{ Financial support and sponsorship } \\
\hline
\end{tabular}

\section{References}

1. Karthikeyan G, Senguttuvan NB, Joseph J, Devasenapathy N, Bahl VK, Airan B. Urgent surgery compared with fibrinolytic therapy for the treatment of left-sided prosthetic heart valve thrombosis: A systematic review and meta-analysis of observational studies. Eur Heart J 2013;34:1557-66.

2. Castilho FM, De Sousa MR, Mendonça AL, Ribeiro AL, Cáceres-Lóriga FM. Thrombolytic therapy or surgery for valve prosthesis thrombosis: Systematic review and meta-analysis. J Thromb Haemost 2014;12:1218-28.

3. Roudaut R, Lafitte S, Roudaut MF, Reant P, Pillois X, Durrieu-Jaïs C, et al. Management of prosthetic heart valve obstruction: fibrinolysis versus surgery early results and longterm follow-up in a single-centre study of 263 cases. Arch Cardiovasc Dis 2009;102:269-77.

4. Huang G, Schaff HV, Sundt TM, Rahimtoola SH. Treatment of obstructive thrombosed prosthetic heart valve. J Am Coll Cardiol 2013;62:1731-6.

5. Özkan M, Gündüz S, Biteker M, Astarcioglu MA, Çevik C, Kaynak E, et al. Comparison of different TEE-guided thrombolytic regimens for prosthetic valve thrombosis: The TROIA trial. JACC Cardiovasc Imaging 2013;6:206-16.

6. Özkan M, Gündüz S, Gürsoy OM, Karakoyun S, Astarcıoğlu MA, Kalçık A. Ultraslow thrombolytic therapy: A novel strategy in the management of prosthetic mechanical valve thrombosis and the predictors of outcome: The ultra-slow prometee trial. Am Heart J 2015;170:409-18.

7. Kathirvel D, Paul GJ, Kumar GP, Palanisamy G, Gnanavelu G, Ravishankar G, et al. Tenecteplase versus streptokinase thrombolytic therapy in patients with mitral prosthetic valve thrombosis. Indian Heart J 2018;70:506-10.

8. Tong AT, Roudaut R, O* zkan M, Sagie A, Shahid MS, Pontes SC Jr., et al. Transesophageal echocardiography improves risk assessment of thrombolysis of prosthetic valve thrombosis: Results of the International PRO-TEE registry. J Am Coll Cardiol 2004;43:77-84.

9. Baumgartner H, Falk V, Bax JJ, De Bonis M, Hamm C, Holm PJ, et al. 2017 ESC/EACTS Guidelines for the management of valvular heart disease. Eur Heart J 2017;38:2739-91.

10. Nishimura RA, Otto CM, Bonow RO, Carabello BA, Erwin JP, Fleisher LA. 2017 AHA/ACC Focused Update of the 2014 AHA/ACC Guideline for the Management of Patients With Valvular Heart Disease: A report of the American College of Cardiology/American Heart Association Task Force on Clinical Practice Guidelines. Circulation 2017;135:1159-95. 